Miller, S. \& Avi-Dor, Y. (1958). J. gen. Microbiol. 18, 221-226

\title{
The Effect of Inorganic Ions on Respiration in Pasteurella tularensis and Escherichia coli
}

\author{
By SHUNAMITH MILLER AND Y. AVI-DOR \\ Israeli Institute for Biological Research, Ness-Ziona, Israel
}

\begin{abstract}
SUMMARY: The effect of the ionic composition of the medium on the respiration of resting-cell suspensions of two Gram-negative micro-organisms has been investigated. Potassium or rubidium salts with $\mathrm{Cl}^{-}, \mathrm{Br}^{-}$or $\mathrm{I}^{-}$as anion were found to be necessary for the maximal rates of oxidation of glutamate or glucose by Pasteurella tularensis, and $\mathrm{KCl}$ or $\mathrm{K}_{2} \mathrm{SO}_{4}$ by Escherichia coli. The $\mathrm{pH}$ value of the medium and the concentration of the substrate influenced the effect of the electrolytes. Under certain conditions, a synergistic effect of $\mathrm{Na}^{+}$ion was observed. The same ion mixtures which supported the respiration caused the maximal swelling of the bacterial cells.
\end{abstract}

The influence of $\mathrm{KCl}$ and $\mathrm{NaCl}$ on the respiration of halophilic bacteria was investigated by Baxter \& Gibbons (1956). Krebs, Whittam \& Hems (1957) showed that the oxidation of various substrates by washed cells of Alcaligenes faecalis was greatly accelerated by potassium ions. In the present communication observations are reported on the effect of various electrolytes on the rate of oxidation of glutamate and glucose by Escherichia coli and by an osmoticallysensitive micro-organism, Pasteurella tularensis.

\section{ME'THODS}

Escherichia coli, strain B, was grown on nutrient agar (Difco). Pasteurella tularensis, strain S and D, was grown on a $3 \%(\mathrm{w} / \mathrm{v})$ peptone (Difco) + cysteine medium (Mager, Kindler \& Grossowicz, 1954). The cultures were incubated at $37^{\circ}$ for $24 \mathrm{hr}$. The bacteria were collected in $0.25 \mathrm{M}$-sucrose and, unless otherwise stated, washed three times with this sucrose solution. The final sucrose $(0 \cdot 25 \mathrm{M})$ suspensions contained $50 \mathrm{mg}$. wet weight organisms $/ \mathrm{ml}$. Manometric experiments were carried out by the conventional Warburg technique. Spectrophotometric examinations were performed in the Beckman model DU spectrophotometer, with Corex cells of $1 \mathrm{~cm}$. light path.

\section{RESULTS}

Effect of various cations and anions on the oxidation of glutamate

Glutamic acid, neutralized by the addition of tris (buffer), 2-amino-2-hydroxymethylpropane-1:3-diol, to $\mathrm{pH} 7 \cdot 4$, was not oxidized by thoroughly washed Pasteurella tularensis when other salts were excluded from the reaction medium. When, however, various potassium salts were added to the bacteria suspended in isotonic sucrose, it was found that $\mathrm{KBr}$ caused the greatest respiratory stimulation, while $\mathrm{KCl}$ and $\mathrm{KI}$ were slightly less effective; other potassium salts had only an insignificant effect. Of the chlorides tested other than $\mathrm{KCl}$ only the 
rubidium salt supported the respiration (Table 1). Since $\mathrm{KCl}$ and the other effective electrolytes enhanced the respiration at relatively low concentrations, their effect could not be due to changes in osmotic pressure (Fig. 1).

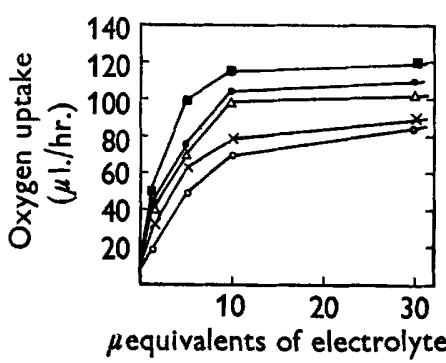

Fig. 1

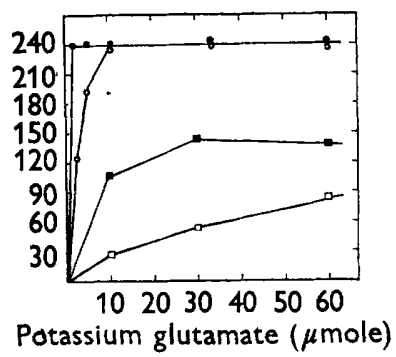

Fig. 2

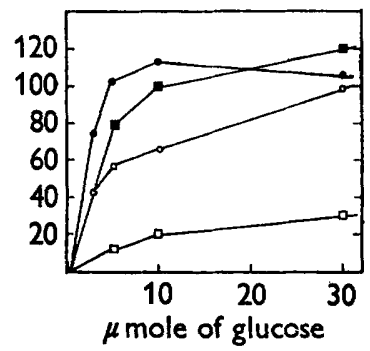

Fig. 3

Fig. 1. Effect of electrolyte concentration. Each flask contained $30 \mu$ mole tris glutamate buffer (pH 7.4), 0.25 M-sucrose, the bacterial suspension (Pasteurella tularensis: $15 \mathrm{mg}$. wet weight; Escherichia coli: $9 \mathrm{mg}$. wet weight) and the electrolyte as indicated. $\mathrm{O}-\mathrm{O}$ and $\bullet-\bullet=\mathrm{KCl} ; \Delta-\Delta=\mathrm{KBr} ; x-x=\mathrm{KI} ; \mathbf{-}-\mathbf{m}=\mathrm{K}_{2} \mathrm{SO}_{4}$. Unshaded marks; and $x-x$ : Pasteurella tularensis. Shaded marks: Escherichia coli. Volume of reaction mixture $3.0 \mathrm{ml}$.; centre well, $0.2 \mathrm{ml}$. of $\mathrm{KOH}$. Temperature, $28^{\circ}$; gas phase, air.

Fig. 2. Effect of concentration of potassium glutamate. Each flask contained $\mathbf{0 \cdot 2 5} \mathrm{M}$ sucrose, the bacterial suspension as in Fig. 1, and potassium glutamate as indicated. $\bigcirc-O$ and $-\bullet=$ Escherichia coli; $\square-\square$ and $\square-\square=$ Pasteruella tularensis. Unshaded marks: no $\mathrm{KCl}$ added; shaded marks : $30 \mu$ mole $\mathrm{KCl}$ added. Conditions of experiment otherwise as in Fig. 1.

Fig. 3. Effect of $\mathrm{KCl}$ on the oxidation of glucose. Each flask contained $60 \mu$ mole tris nitrate buffer $(\mathrm{pH} \mathrm{7.4)} 0.25 \mathrm{M}$-sucrose and glucose as indicated. Escherichia coli and Pasteurella tularensis as in Fig. $1 . \bigcirc-\bigcirc$ and $--\bullet=$ Escherichia coli; $\square-\square$ and $\square-\square=$ Pasteurella tularensis. Unshaded marks : no $\mathrm{KCl}$ added; shaded marks; $30 \mu$ mole $\mathrm{KCl}$ added. The conditions of the experiment otherwise as in Fig. 1.

Escherichia coli likewise was incapable of metabolizing glutamate neutralized by tris (buffer); addition of $\mathrm{KCl}$ or $\mathrm{K}_{2} \mathrm{SO}_{4}$ was necessary for oxidation of the substrate, but rubidium could not replace the potassium (Table 1, Fig. 1). In order to elucidate the part played by the cation, the rate of oxidation of glutamate in various counter-ion combinations was measured. Sodium glutamate was not oxidized by either of the two micro-organisms. In Pasteurella tularensis, the rate of oxidation of potassium glutamate increased with the concentration of the substrate, and the highest rate of respiration was attained only when $\mathrm{KCl}$ was added. In suspensions of Escherichia coli, $\mathrm{KCl}$ accelerated the oxidation of potassium glutamate only when the concentration of the substrate was suboptimal (Fig. 2).

\section{Effect of $\mathrm{KCl}$ on the oxidation of glucose}

Acceleration of the rate of glucose oxidation by the addition of $\mathrm{KCl}$ was also demonstrated. In Pasteurella tularensis, the effect was observed at all concentrations of substrate, while in Escherichia coli it became apparent only at low glucose concentrations (Fig. 3). 


\section{Effect of $\mathrm{pH}$ value}

The effect of the $\mathrm{pH}$ value on the oxidation of glutamate and glucose was studied in Pasteurella tularensis. As shown in Fig. 4, the rate of oxidation of both substrates diminished with decreasing acidity. The stimulation caused by $\mathrm{KCl}$ became most prominent at slightly alkaline $\mathrm{pH}$ values.

Table 1. The effect of electrolytes on the oxidation of tris glutamate buffer by Escherichia coli and Pasteurella tularensis

Each flask contained $30 \mu$ mole of tris glutamate buffer $(\mathrm{pH} 7 \cdot 4), 0 \cdot 25 \mathrm{M}$-sucrose. The final concentration of the electrolytes was $30 \mu$ equiv./cup when one salt was added and $15 \mu$ equiv./ cup each salt when a mixture of two was used. Volume of reaction mixture $3.0 \mathrm{ml}$.

\begin{tabular}{|c|c|c|c|c|c|c|c|c|c|}
\hline \multirow{3}{*}{ Anion } & \multirow{2}{*}{\multicolumn{7}{|c|}{ Cation }} & \multicolumn{2}{|c|}{ Organism } \\
\hline & & & & & & & & \multirow{2}{*}{\multicolumn{2}{|c|}{$\begin{array}{l}\text { E. coli P. tularensis } \\
\text { Oxygen uptake }(\mu \mathrm{l} . / \mathrm{hr} \text {. }\end{array}$}} \\
\hline & $\mathbf{K}^{+}$ & $\mathrm{Na}^{+}$ & $\mathrm{Li}^{+}$ & $\mathrm{Rb}^{+}$ & $\mathrm{NH}_{4}^{+}$ & $\mathrm{Ca}^{++}$ & $\mathrm{Mg}^{++}$ & & \\
\hline \multirow{7}{*}{ Chloride } & + & . & . & . & . & . & . & 186 & 120 \\
\hline & . & + & . & . & . & . & . & 60 & 17 \\
\hline & - & . & + & . & . & . & . & 0 & 45 \\
\hline & . & . & . & + & . & . & . & 0 & 142 \\
\hline & . & . & . & . & + & . & . & 0 & 0 \\
\hline & . & - & . & . & . & + & . & 40 & 0 \\
\hline & - & - & - & - & - & $\cdot$ & + & $\mathbf{0}$ & 42 \\
\hline \multirow{3}{*}{ Bromide } & + & . & . & . & . & . & . & 10 & 154 \\
\hline & . & + & - & . & . & . & . & 0 & - \\
\hline & + & + & . & . & . & . & . & 138 & . \\
\hline Iodide & + & . & . & . & . & . & . & 15 & 106 \\
\hline \multirow[t]{9}{*}{ Nitrate } & + & . & . & . & . & . & . & 0 & 0 \\
\hline & . & + & . & - & - & . & . & 12 & 0 \\
\hline & . & . & + & . & . & . & . & 0 & . \\
\hline & . & . & . & . & . & + & . & o & . \\
\hline & . & . & . & . & . & . & + & 0 & . \\
\hline & + & + & . & . & . & . & . & 185 & 34 \\
\hline & + & . & + & . & . & . & . & 0 & . \\
\hline & + & - & . & . & . & - & + & 0 & - \\
\hline & + & - & . & - & • & + & · & $\mathbf{0}$ & • \\
\hline \multirow[t]{3}{*}{ Sulphate } & + & . & . & . & . & . & . & 185 & 35 \\
\hline & . & + & . & . & . & . & . & 0 & 20 \\
\hline & + & + & . & . & . & . & . & 147 & 20 \\
\hline \multirow[t]{4}{*}{ Phosphate } & + & . & . & . & . & . & . & $\mathbf{0}$ & 47 \\
\hline & . & + & . & . & . & . & . & 0 & . \\
\hline & + & + & . & . & . & - & - & 153 & - \\
\hline & . & . & . & . & . & . & . & 0 & 0 \\
\hline
\end{tabular}

Controls containing each electrolyte but no glutamate showed no oxygen uptake.

The synergistic effect of $\mathrm{Na}^{+}$ions

The suppression of the oxidation of glutamate in Escherichia coli in the presence of potassium salts other than chloride and sulphate (i.e. $\mathrm{NO}_{3}^{-}, \mathrm{HPO}_{4}^{-}$, etc.) can be counteracted by the addition of $\mathrm{Na}^{+}$ions, irrespective of the anionic moiety (Table 1 ). $\mathrm{Li}^{+}, \mathbf{R b}^{+}, \mathrm{Mg}^{++}$or $\mathrm{Ca}^{++}$could not replace $\mathrm{Na}^{+}$in this respect. 


\section{Effect of electrolytes on changes in the state of swelling of bacterial cells}

When a suspension of Pasteurella tularensis was added to a medium containing $\mathrm{KCl}$ alone, or glutamate neutralized with tris (buffer), only slow swelling was observed. In a mixture of the substrate + the electrolyte, however, the optical

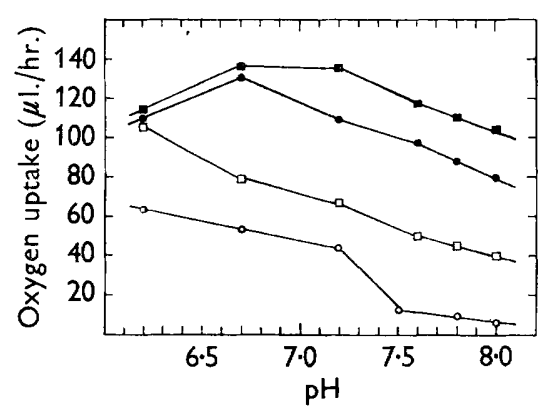

Fig. 4

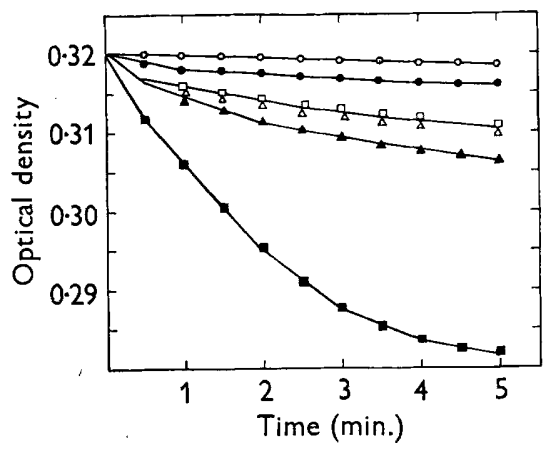

Fig. 5

Fig. 4. Effect of $\mathrm{pH}$ value. Each flask contained: $60 \mu \mathrm{mole}$ tris phosphate buffer of the respective $\mathrm{pH}$ value; $30 \mu$ mole substrate; $0.25 \mathrm{M}$-sucrose; Pasteurella tularensis as in Fig. 1. $\bigcirc-\bigcirc$ and $\bigcirc-\bigcirc=$ glutamate; $\square-\square$ and $\square-\square=$ glucose. Unshaded marks : no $\mathrm{KCl}$ added; shaded marks $30 \mu$ mole $\mathrm{KCl}$ added. Conditions of the experiment otherwise as in Fig. 1.

Fig. 5. Effect of glutamate and electrolytes on turbidity changes. Each Beckman cell contained : $0 \cdot 25 \mathrm{M}$-sucrose and tris glutamate buffer and/or electrolytes as indicated. $\mathrm{O}-\mathrm{O}=$ no addition ; $-1=30 \mu$ mole tris glutamate buffer $\square-\square=30 \mu$ mole $\mathrm{KCl} ; \triangle-\triangle=30 \mu \mathrm{mole}$ $\mathrm{KNO}_{3} ; \mathbf{\square}-\mathbf{\square}=\mathbf{3 0} \mu$ mole glutamate $+\mathrm{KCl} ; \mathbf{\Delta}-\mathbf{\Delta}=\mathbf{3 0} \mu$ mole glutamate $+\mathrm{KNO}_{3}$. Total volume $3.0 \mathrm{ml}$. At zero time $0.05 \mathrm{ml}$. of a dense suspension of Pasteurella tularensis added. Control cell, water. Room temperature. Optical density measured at wavelength $500 \mathrm{~m} \mu$.

density of the suspension decreased rapidly and exponentially until a new state of equilibrium was reached. Like $\mathrm{KCl}, \mathrm{KBr}$ and $\mathrm{KI}$ accelerated swelling but other potassium salts had no effect (Fig. 5). In an experiment with a suspension of Escherichia coli, $\mathrm{KCl}, \mathrm{K}_{2} \mathrm{SO}_{4}$ or a mixture of $\mathrm{KNO}_{3}+\mathrm{NaNO}_{3}$ was found to promote swelling.

\section{DISCUSSION}

The effect of electrolytes on the respiration of a variety of biological systems has been described before. Acceleration of the respiration of brain cortex slices by chlorides, bromides or iodides of either potassium, rubidium or caesium has been demonstrated (Ashford \& Dixon, 1935; Dickens \& Greville, 1935). The stimulation of glucose oxidation in rat-liver homogenates by $\mathbf{K}^{+}, \mathbf{R b}^{+}, \mathrm{Cs}^{+}$, $\mathrm{Mg}^{++}$was reported by Haugaard \& Itzkovitz (1956); on addition of $\mathrm{NaCl}$, $\mathrm{LiCl}$ or $\mathrm{CaCl}_{2}$ to a system activated by potassium ions, glucose oxidation was inhibited. In Alcaligenes faecalis washed with distilled water, Krebs $e t$ al. (1957) demonstrated an acceleration of the rate of oxidation of various substrates by the addition of $\mathrm{K}^{+}$or $\mathbf{R} \mathbf{b}^{+}$ions. These authors attributed the activity of $\mathrm{Rb}^{+}$to contamination with potassium salts. In the present work, the same 
batch of rubidium chloride which replaced $\mathbf{K}^{+}$in Pasteurella tularensis proved to be quite ineffective on the oxidation of glutamate in Escherichia coli. In this case, therefore, the action of $\mathbf{R b}^{+}$cannot be attributed to small amounts of $\mathrm{K}^{+}$present as impurity. In Alcaligenes faecalis, accumulation of $\mathrm{K}^{+}$ions was shown to occur during the incubation and could be accounted for by exchange diffusion. The penetration of $\mathrm{K}^{+}$was not accompanied by a similar movement of the anion, and moreover the nature of the anion was without influence on the rate of acceleration of the respiration. In contrast to these findings, $\mathrm{K}^{+}$ion was effective only in certain counter-ion combinations in Escherichia coli and Pasteurella tularensis. Exchange diffusion seems, therefore, to play a smaller part in this case. It might be relevant to this point that, in the case of Escherichia coli, potassium salts which alone caused no stimulation of the respiration, could be activated by the addition of any sodium salt which by itself was similarly ineffective. A promoting effect on the exchange diffusion of potassium by sodium ions, overcoming thereby the retardation due to the anion, might be involved in this phenomenon. The control of the influx of $\mathrm{K}^{+}$ions by the $\mathrm{Na}^{+}$concentration in the medium into erythrocytes and nerve fibres has repeatedly been demonstrated (Conway, 1954). Krebs et al. (1957) have also shown that $\mathrm{Na}^{+}$ions facilitate the accumulation of $\mathrm{K}^{+}$ in the bacterial cell.

As potassium glutamate is oxidized by Escherichia coli at maximum rate without the addition of other electrolytes, the anion has probably only an indirect effect. The anion might exert a modifying action on the permeability of the cation, due to the different diffusion potentials created (Davson, 1940). The effectiveness of the halogen salts of potassium and rubidium in Pasteurella tularensis is in accordance with this view, as biological membranes are known to be permeable to $\mathrm{Cl}^{-}, \mathrm{Br}^{-}$and $\mathrm{I}^{-}$ions (Conway, 1954). The penetration of the cation used as its halogen salt will thus not be hindered by its counter-ion. The ready penetration of the sulphate ion in Escherichia coli, on the other hand, could not be anticipated.

Correlation between the swelling of ascites cells suspended in media containing various substrates and the accumulation of the metabolites in the cell interior has been demonstrated before (Christensen, Riggs, Fisher \& Palatine, 1952). The finding that the same ion combination, which accelerated the oxidation of substrates in the micro-organisms studied, was also the most effective in eliciting the swelling of the bacteria (Mager, Kuczynski, Schatzberg \& AviDor, 1956; Avi-Dor, Kuczynski, Schatzberg \& Mager, 1956) could possibly be interpreted as the effect of the ionic environment on the rate of penetration of the substrate. The latter might become the rate limiting step under certain experimental conditions (higher $\mathrm{pH}$ values, low substrate concentration). Hence, the increased dependence of the respiration on the addition of $\mathrm{K}^{+}$ions under such conditions. 


\section{REFERENCES}

Ashford, C. A. \& Dixon, K. C. (1935). The effect of potassium on the glucolysis of brain tissue with reference to the Pasteur effect. Biochem. J. 29, 157.

Avi-Dor, Y., Kuczynskr, M., Schatzberg, G. \& Mager, J. (1956). Turbidity changes in bacterial suspensions: kinetics and relation to metabolic state. J. gen. Microbiol. 14, 76.

Baxter, R. M. \& Gibbons, N. E. (1956). Effects of sodium and potassium chloride on certain enzymes of Micrococcus halodenitrificans and Pseudodomonas salinaria. J. gen. Microbiol. 2, 599.

Christensen, H. N., Riggs, T. R., Fisher, H. \& Palatine, I. M. (1952). Intense concentration of $\alpha$ - $\gamma$-diaminobutyric acid by cells. J. biol. Chem. 198, 15.

Conway, E. J. (1954). Some aspects of ion transport through membranes in Symp. Soc. exp. Biol. 8, 297.

Davson, H. (1940). The influence of lyotropic series of anion on cation permeability. Biochem. J. 34, 917.

Dickens, F. \& Greville, G. D. (1935). The metabolism of normal and tumor tissues. Biochem. J. 29, 1468.

Haugaard, N. \& Itzkovitz, H. (1956). Hexose oxidation by rat heart homogenate of a multienzyme system. Arch. Biochem. Biophys. 65, 229.

Krebs, H. A., Whittam, R. \& Hems, R. (1957). Potassium uptake by Alcaligenes faecalis. Biochem. J. 66, 53.

Mager, J., Kindler, S. H. \& Grossowicz, N. (1954). Nutritional studies with Clostridium parabotulinum. J.gen. Microbiol. 10, 130.

Mager, J., Kuczynski, M., Schatzberg, G. \& Avi-Dor, Y. (1956). Turbidity changes in bacterial suspensions in relation to osmotic pressure. J. gen. Microbiol. 14, 69. 